\title{
Infectious Mononucleosis: A Case Report With Unusual Features and Abnormal Laboratory Findings
}

\author{
Ammar Alli ${ }^{1,2}$, Farah Nabil ${ }^{3}$, Juan Fernando Ortiz ${ }^{4,5}$ \\ 1. Internal Medicine, Tishreen University Faculty of Medicine, Latakia, SYR 2. Internal Medicine, Universitat de \\ Barcelona, Barcelona, ESP 3. Faculty of Health Sciences, University of Zaragoza, Zaragoza, ESP 4. Neurology, \\ Universidad San Francisco de Quito, Quito, ECU 5. Neurology, Larkin Community Hospital, Miami, USA
}

Corresponding author: Juan Fernando Ortiz, sumjuanfer41@gmail.com

\begin{abstract}
Despite the widespread Epstein-Barr virus (EBV) infections, we continue to see new reports with strange and unusual manifestations of the infection, which raises the question of how well we understand this pathogen. The age of contracting the infection is increasing in developed countries, which is changing the clinical presentation of those who get infected during their adolescence or early adulthood. In these stages, liver involvement is more prominent, and other physical symptoms are less apparent. Therefore, an update on infectious mononucleosis (IM) variable manifestation is required to make healthcare providers aware of this shift. This case stands as an example of the new shift as a patient scheduled for elective surgery suddenly presented with subclinical hepatitis caused by primary EBV infection. Our patient presented with few physical symptoms but had a classical picture of EBV-induced hepatitis on blood analysis. The diagnosis was missed by many physicians due to the varied presentations of IM. This case corresponds to the new evidence that suggests that hepatic involvement is one of the most prominent manifestation in the adult population with primary EBV infection.
\end{abstract}

Review began 04/18/2021 Review ended 04/27/2021 Published 05/01/2021

\section{Copyright 2021}

Alli et al. This is an open access article distributed under the terms of the Creative Commons Attribution License CC-BY 4.0., which permits unrestricted use, distribution, and reproduction in any medium, provided the original author and source are credited.
Categories: Infectious Disease

Keywords: epstein-barr virus, infectious mononucleosis

\section{Introduction}

Epstein-Barr virus (EBV) is a member of the herpes family and one of the most common viruses known to infect humans. It is estimated that $90 \%$ of the general population becomes infected with the virus before the age of 30 [1]. However, in most cases, the infection is self-limiting and rarely leads to dangerous complications; fewer than $1 \%$ of cases experience serious complications [1].

EBV infection ranges from asymptomatic disease to a spectrum of illnesses. Similar to most viral infections, children are usually asymptomatic, while young adults show the classic symptoms of infectious mononucleosis (IM). Patients older than 60 years frequently present with jaundice, minor lymphadenopathy, sore throat, and splenomegaly [2].

Liver involvement is seen in $80-90 \%$ of IM cases. It is mainly characterized by a transitory elevation of liver enzymes [3]. The self-limiting and benign nature of the infection hinder healthcare providers' ability to diagnose certain primary EBV cases and answer patient's question regarding the infection course. Here, we present an unconventional IM case with an atypical presentation and an unusual liver laboratory pattern, which differs from the traditional patterns of the infection.

This case aims to bring healthcare providers' attention to the different manifestations of IM in young individuals compared to adolescents as the disease mainly presents as subclinical hepatitis with no other symptoms.

\section{Case Presentation}

A 29-year-old Syrian man called his primary care physician on day one before his scheduled elective surgery on day six. He initially complained of having "white spots” on his right tonsil. The General Practitioner (GP) prescribed him antibiotics immediately, assuming he had streptococcal pharyngitis.

On the second day, the patient came to the clinic for further evaluation. On physical examination, the patient had two inflamed lymph nodes below the jaw and an extensive membrane covering the right tonsil. His temperature was $37.0^{\circ} \mathrm{C}$. He was prescribed intramuscular ceftriaxone twice a day along with $2 \mathrm{~g}$ of oral amoxicillin per day. His physical examination was otherwise normal. He reported no fever, malaise, or any sore throat. He reported that he sought medical help only because he had a scheduled surgery and wanted to make sure everything was alright. 


\section{Cureus}

On the fourth day, the patient was referred to an otolaryngologist for further evaluation. His left tonsil started showing increasing numbers of white spots as well. No improvement was seen on the tonsils. The otolaryngologist repeated the physical and confirmed the findings of the GP, and instructed the patient to continue with the antibiotics.

On the fifth day, the patient visited the infectious disease department in a local hospital, where the resident doctor instructed him to stop the medications and order some lab work for him.

On the sixth day, the lab results came back confirming a diagnosis of IM. The patient was asked to follow-up with the infectious disease department weekly to monitor his condition. Table 1 shows the first laboratory results of the patient.

\begin{tabular}{|l|l|l|}
\hline Blood analysis first week & Patient's results & Normal range \\
\hline While blood cells & $10,800(62 \%$ lymphocytes $)$ & $4,500-10,500 / \mathrm{mm}^{3}$ \\
\hline ASLO & 29 & Up to $200 \mathrm{IU} / \mathrm{mL}$ \\
CRP & 8.9 & Up to $6 \mathrm{mg} / \mathrm{L}$ \\
ALT & 370 & Up to $41 \mathrm{U} / \mathrm{L}$ \\
AST & 188 & Up to $37 \mathrm{U} / \mathrm{L}$ \\
ALP & 181 & $40-129 \mathrm{U} / \mathrm{L}$ \\
\hline Monospot test & Positive & Negative \\
\hline
\end{tabular}

TABLE 1: Laboratory results of the patients.

ALP: alkaline phosphatase; ALT: alanine transaminase; ASLO: anti-streptolysin O; AST: asparate transaminase; CRP: C-reactive protein

Table 2 shows the second blood analysis of the patient.

\begin{tabular}{|c|c|c|}
\hline Blood analysis second week & Patient's results & Normal range \\
\hline White blood cells & 7,300 (59\% lymphocytes) & $4,500-10,500 / \mathrm{mm}^{3}$ \\
\hline CRP & 2.3 & Up to $6 \mathrm{mg} / \mathrm{L}$ \\
\hline ALT & 417 & Up to $41 \mathrm{U} / \mathrm{L}$ \\
\hline AST & 108 & Up to $37 \mathrm{U} / \mathrm{L}$ \\
\hline ALP & 184 & $40-129 \mathrm{U} / \mathrm{L}$ \\
\hline
\end{tabular}

TABLE 2: Laboratory results of the patient.

ALP: alkaline phosphatase; ALT: alanine transaminase; AST: asparate transaminase; CRP: C-reactive protein

Table 3 shows the third blood analysis of the patient. 


\section{Cureus}

\begin{tabular}{|c|c|c|}
\hline Blood analysis third week & Patient's results & Normal range \\
\hline White blood cells & 7,900 (54\% lymphocytes) & $4,500-10,500 / \mathrm{mm}^{3}$ \\
\hline ALT & 154 & Up to $41 \mathrm{U} / \mathrm{L}$ \\
\hline ASI & 50 & Up to $3 / \mathrm{U} / \mathrm{L}$ \\
\hline ALP & 141 & $40-129 \mathrm{U} / \mathrm{L}$ \\
\hline Gamma GT & 71 & $11-51 \mathrm{U} / \mathrm{L}$ \\
\hline
\end{tabular}

\section{TABLE 3: Laboratory results of the patient.}

ALP: alkaline phosphatase; ALT: alanine transaminase; AST: asparate transaminase; Gamma GT: gamma glutamyltranspeptidase

Table 4 shows the fourth blood analysis of the patient.

\begin{tabular}{|l|l|l|}
\hline Blood analysis fourth week & Patient's results & Normal range \\
\hline White blood cells & $7,700(37 \%$ lymphocytes $)$ & $4,500-10,500 / \mathrm{mm}^{3}$ \\
\hline ALT & 81 & Up to $41 \mathrm{U} / \mathrm{L}$ \\
AST & 16 & Up to $37 \mathrm{U} / \mathrm{L}$ \\
\hline ALP & 114 & $40-129 \mathrm{U} / \mathrm{L}$ \\
\hline Gamma GT & 51 & $11-51 \mathrm{U} / \mathrm{L}$ \\
\hline
\end{tabular}

\section{TABLE 4: Laboratory results of the patient.}

ALP: alkaline phosphatase; ALT: alanine transaminase; AST: asparate transaminase; Gamma GT: gamma glutamyltranspeptidase

\section{Discussion}

EBV is one of the most common viruses that are known to cause or be associated with a variety of human diseases. Understanding primary EBV infection with its variable range of manifestations is crucial to diagnose patients, better evaluate the infection course, and provide better care. On physical examination, only two classical symptoms were present in our patient: two enlarged cervical lymph nodes and pseudomembranous tonsillitis. Therefore, many physicians missed the initial diagnosis. Nevertheless, blood work showed an extensive picture of EBV with one of its most common manifestations, transient mild hepatitis.

\section{Diagnosis and features of the infection compared to our case}

In the literature, the most common symptoms of IM include sore throat (94\%), cervical lymphadenopathy (81\%), fatigue (72\%), and upper respiratory symptoms (64\%) [1]. The clinical triad of fever, sore throat, and lymphadenopathy is considered an indicator for primary EBV infection.

A study reported that patients with IM developed a rash at a rate of almost 100\% after receiving penicillin which was explained as a period of transient hypersensitivity toward penicillin during the course of the infection $[4,5]$. The incidence of different lab results varied between studies.

In our case, the patient presented with two enlarged cervical lymph nodes and a pseudomembrane on his tonsils. Other classical IM symptoms were not present. His physical examination and vital signs were within normal limits. After receiving aggressive treatment with PO amoxicillin $2 \mathrm{~g}$ /day and intramuscular ceftriaxone $2 \mathrm{~g} /$ day for four days, the patient did not develop any rash, even though most IM patients develop a rash after penicillin therapy.

The patient was diagnosed after his Monospot test came positive. Studies show that $85-90 \%$ of young people test positive on Monospot test during the course of EBV infection [6], securing an accuracy rate of $71 \%$ to $90 \%$ for the diagnosis of IM [2]. The patient's peripheral blood smear showed more than $10 \%$ of atypical 
lymphocytes. The elevated transaminases and lymphocytosis were helpful in confirming the diagnosis.

\section{Liver involvement}

In primary EBV, liver involvement is seen in more than $80 \%$ of cases [3]. Therefore, it is important to understand this aspect of the disease. Liver enzymes including alanine aminotransferase (ALT), aspartate aminotransferase (AST), alkaline phosphatase (ALP), and gamma glutamyltranspeptidase (gamma GT) are elevated. The predominant type is a transient cholestatic (conjugated hyperbilirubinemia, elevated ALP, and gamma GT) liver disease seen in $59 \%$ of cases [3].

\begin{tabular}{|c|c|c|}
\hline Liver enzymes & Our patient & Expected increase due to EBV \\
\hline ALT & 370-417 U/L & Up to $205 \mathrm{U} / \mathrm{L}$ \\
\hline AST & 188-108 U/L & Up to185 U/L \\
\hline
\end{tabular}

\section{TABLE 5: Comparison of expected liver enzymes and liver enzymes of our patient.}

ALT: alanine aminotransferase; AST: aspartate aminotransferase; EBV: Epstein-Barr virus

According to recent studies, EBV hepatitis frequency increases with age [7]. Thus, healthcare providers should consider EBV as a possible cause of hepatitis where mild elevation of transaminases is reported. During EBV, hepatitis elevation of transaminase is usually mild; in other words, it is less than five-fold of the normal levels [3]. As seen in our patient, ALT elevation of more than five-fold is less common and very unusual.

EBV hepatitis is benign and self-limiting. However, a proper understanding of its course is beneficial to educate healthcare providers when they encounter surprising laboratory results and answer patients' questions about the infection pattern.

A study that included 47 primary EBV patients showed that the rise of ALT peaked three times on days 8,11 , and 13 (during the second week); AST peaked two times on days 8 and 11 (also during the second week); ALP peaked randomly and remained elevated even after 30 days, and gamma GT peaked one time after 15 days [3]. Our patient had an increase in ALT levels in the second week, consistent with the normal variations and peaks seen in other studies. It is important to know that these variations are normal, carry no clinical significance, and are not correlated with the changes to other findings such as lymphocytosis [3].

After his second blood analysis, our patient felt anxious as he had an increased ALT (370 increased to 417 $\mathrm{U} / \mathrm{L}$ ). Therefore, he was instructed to follow a low-fat diet rich in carbohydrates. According to the literature, these variations were normal and did not require following restrictive diets. Nevertheless, this approach was considered a precarious measure.

\section{Conclusions}

In conclusion, despite the financial and technical difficulties that healthcare providers and patients face currently in Syria, this case is unique as it shows few clinical findings consistent with primary EBV. However, it documents an important manifestation of EBV-induced hepatitis in a young, healthy adult male. This study sheds light on the importance of recognizing primary EBV in older populations and taking into account the possible decrease in classic IM symptoms and the increasing likelihood of subclinical hepatitis.

\section{Additional Information}

\section{Disclosures}

Human subjects: Consent was obtained or waived by all participants in this study. Conflicts of interest: In compliance with the ICMJE uniform disclosure form, all authors declare the following: Payment/services info: All authors have declared that no financial support was received from any organization for the submitted work. Financial relationships: All authors have declared that they have no financial relationships at present or within the previous three years with any organizations that might have an interest in the submitted work. Other relationships: All authors have declared that there are no other relationships or activities that could appear to have influenced the submitted work.

\section{References}

1. Dunmire SK, Hogquist KA, Balfour HH: Infectious mononucleosis. Curr Top Microbiol Immunol. 2015, 390:211-40. 10.1007/978-3-319-22822-8 9 


\section{Cureus}

2. Womack J, Jimenez M: Common questions about infectious mononucleosis. Am Fam Physician. 2015, 91:372-6.

3. Kofteridis DP, Koulentaki M, Valachis A, Christofaki M, Mazokopakis E, Papazoglou G, Samonis G: Epstein Barr virus hepatitis. Eur J Intern Med. 2011, 22:73-6. 10.1016/j.ejim.2010.07.016

4. Balfour HH Jr, Forte FA, Simpson RB, Zolov DM: Penicillin-related exanthems in infectious mononucleosis identical to those associated with ampicillin. Clin Pediatr (Phila). 1972, 11:417-21. $10.1177 / 000992287201100711$

5. González Saldaña N, Monroy Colín VA, Piña Ruiz G, Juárez Olguín H: Clinical and laboratory characteristics of infectious mononucleosis by Epstein-Barr virus in Mexican children. BMC Res Notes. 2012, 5:361. 10.1186/1756-0500-5-361

6. De Paschale M, Clerici P: Serological diagnosis of Epstein-Barr virus infection: problems and solutions . World J Virol. 2012, 1:31-43. 10.5501/wjv.v1.i1.31

7. Kang MJ, Kim TH, Shim KN, Jung SA, Cho MS, Yoo K, Chung KW: Infectious mononucleosis hepatitis in young adults: two case reports. Korean J Intern Med. 2009, 24:381-7. 10.3904/kjim.2009.24.4.381 